\title{
Difficult-to-treat and severe asthma in general practice: delivery and evaluation of an educational program
}

\author{
Isla Hains ${ }^{1 *}$ (D, Josh Meyers ${ }^{1}$, Kirsten Sterling ${ }^{1}$, Jeannie Yoo ${ }^{1}$, Helen Reddel ${ }^{2}$ and Clare Weston ${ }^{1}$
}

\begin{abstract}
Background: Asthma, a common yet complex airway disorder affecting about 11\% of Australians, is well-controlled in only $54 \%$ of people with asthma. Those with difficult-to-treat and severe asthma are more likely to experience recurrent and potentially life-threatening exacerbations. It is therefore important that GPs can initiate a systematic approach for the management of patients with difficult-to-treat asthma to identify those whose condition may improve by addressing contributory factors and those who require specialist input. We therefore aimed to develop and deliver an educational program for GPs on the systematic management of patients with difficult-to-treat and severe asthma and evaluate the effectiveness of this program.
\end{abstract}

Methods: We developed an educational program on the management of difficult-to-treat and severe asthma in primary care that was delivered to GPs and other health professionals between January and June 2018. We evaluated the effectiveness of the program using a retrospective pre-test with post-survey, administered to GPs directly after program participation.

Results: Over 1000 general practice health professionals participated in the educational program, including 890 GPs of whom 226 (25\%) completed the survey. Following program participation, a greater proportion of GPs identified factors they would assess in managing a patient with poor asthma control, particularly for considering the risk of future adverse outcomes (+ 51\%), changes in lifestyle (+38\%), and self-management strategies (+ 35\%). GPs indicated a greater awareness of the biologic therapies that specialists could consider prescribing to their patients with severe asthma (+ 75\%), of the requirements for a patient to be prescribed a biologic therapy (+ 73\%) and that patients with different phenotypic characteristics can respond differently to standard therapy (+67\%). The proportion of GPs who would refer appropriate patients to a specialist also significantly increased.

Conclusions: This study suggests that an evidence-based educational program can improve GP knowledge, confidence and intended practice in managing patients with difficult-to-treat and severe asthma.

Keywords: Asthma, Severe asthma, Difficult-to-treat asthma, Uncontrolled asthma, Evaluation, Medical education, Training, Quality improvement, General practitioner

\footnotetext{
* Correspondence: ihains@nps.org.au

${ }^{1}$ NPS MedicineWise, PO Box 1147, Strawberry Hills, NSW 2012, Australia

Full list of author information is available at the end of the article
}

(c) The Author(s). 2019 Open Access This article is distributed under the terms of the Creative Commons Attribution 4.0 International License (http://creativecommons.org/licenses/by/4.0/), which permits unrestricted use, distribution, and reproduction in any medium, provided you give appropriate credit to the original author(s) and the source, provide a link to the Creative Commons license, and indicate if changes were made. The Creative Commons Public Domain Dedication waiver (http://creativecommons.org/publicdomain/zero/1.0/) applies to the data made available in this article, unless otherwise stated. 


\section{Background}

Asthma is a common yet complex airway disorder that affects approximately $11 \%$ of the Australian population [1]. A 2012 Australian survey found that asthma was well-controlled in only 54\% of people with asthma [2]. The management of adults with asthma that remains uncontrolled despite treatment with high-dose therapies is challenging for both clinicians and patients [3]. Although most people's asthma can be effectively treated by general practitioners (GPs) with available medicines, a significant population has uncontrolled asthma despite high-dose treatment. These patients are categorised as having difficult-to-treat asthma [4]. Poor asthma control in these patients is most commonly due to factors other than asthma itself - including poor adherence to treatment or incorrect inhaler technique [5]. This is not the case however for those with true severe asthma, whose asthma remains uncontrolled or fails to improve despite treatment optimisation, confirmation of the diagnosis and treatment of confounders [6]. Severe asthma is a subset of difficult-to-treat asthma and these definitions are commonly misunderstood by healthcare professionals [3, 4]. Patients with severe asthma, who make up 3 to $10 \%$ of the population of adults with asthma, are at increased risk for medication-related side-effects, and are more likely to experience recurrent and potentially life-threatening exacerbations [7].

Unlike other disease conditions, asthma severity is assessed retrospectively based on the level of treatment required to achieve good asthma control. It can therefore only be assessed when a patient has been on inhaled anti-inflammatory therapy, commonly called a 'preventer' (or controller), for several months $[6,8]$. Asthma control, however, is described in terms of both recent symptom control and future risk of adverse outcomes [5]. Asthma control and severity are not synonymous and should not be used interchangeably [5, 9].

Recent advances in the understanding of the pathophysiology of asthma, and recognition of its phenotypic heterogeneity, have prompted the development of new biologic medicines for the treatment of severe asthma [10]. However, GPs may be unfamiliar with this relatively new group of medicines and their availability. These medicines can offer important clinical benefits to selected patients whose asthma is relatively refractory to conventional treatment [11]. Biologic therapies are expensive, and within Australia government subsidies to help with medicine costs via the Pharmaceutical Benefits Scheme (PBS) are only available for patients who meet strict criteria [12-14]. It is therefore important that GPs can initiate a systematic approach for the management of patients with difficult-to-treat asthma to identify those who may improve by addressing contributory factors and identify those who require specialist input [5].
NPS MedicineWise is an independent, not-for-profit and evidence-based organisation that works to improve the way medicines, medical tests and health technologies are prescribed and used in Australia. We offer a visiting education service for health professionals and deliver over 25,000 face-to-face visits each year to GPs in their practices. Visits are delivered by a national team of educational visitors either one-to-one or in small group meetings, supporting achievement of quality use of medicines and other health technologies through evidencebased academic detailing.

The aims of this study were to develop and deliver an educational visiting program to GPs on the systematic guidelines-based management of patients with difficultto-treat and severe asthma and to evaluate the changes in GP knowledge and intended practice as a result of this program.

\section{Methods}

\section{Participants and setting}

We designed an educational program that focused on the management of difficult-to-treat and severe asthma in primary care. This program was delivered by NPS MedicineWise educational visitors to GPs and their interested practice staff (e.g., practice nurses, Aboriginal health workers) at Australian general practices in the states of New South Wales, Queensland and Victoria, between January 2018 and June 2018.

Delivery of the program was targeted to reach GPs in areas where there were higher rates of uncontrolled asthma, as indicated by higher asthma-related healthcare utilisation. The target delivery areas were identified using:

- analysis of MedicineInsight data to identify areas with high rates of asthma-related GP encounters. MedicineInsight is an Australian general practice data program developed and managed by NPS MedicineWise, with funding support from the Australian Government Department of Health [15]. It is a large-scale national general practice data program that extracts and collates longitudinal, de-identified patient health records from selected clinical information systems. These data are used for research, to inform health care decision making and policy [16-18].

- Australian Atlas of Healthcare Variation to identify areas with high rates of hospital admissions for asthma among people aged 20-44 years (standardised for population density) [19].

For visits in this program, we prioritised areas with both high hospitalisation rates and high rates of asthma-related GP encounters in regional and metropolitan areas. 


\section{Education program design}

We designed the educational program based on academic detailing principles, which have been shown to be effective in influencing health professionals' knowledge and practice $[20,21]$. The program content was informed by a review of the literature, key informant interviews with practising GPs, and an extensive stakeholder consultation process that included engagement with national asthma organisations as well as several expert respiratory physicians and GPs.

This process enabled the development of evidencebased program objectives, key education messages and a framework for delivering the educational program to small groups of GPs and allied health staff in their practices (Table 1). The program was delivered through a facilitated face-to-face 1-h meeting which included a discussion of the key messages (see Table 1) as well as discussion of how to differentiate between difficult-totreat and severe asthma, modifiable factors that may contribute to poor symptom control, a treatment and referral pathway algorithm and a summary of currently available biologic therapies.

Resources to support the educational program were developed and pilot tested with GPs. These resources included:

a) a GP handout - a paper resource (see Additional file 1) with detailed program content designed to support and complement the discussion between the GP and educational visitor. This was left with GPs for reference. Two case studies were included in this resource to facilitate peer group discussion of a systematic approach to managing patients with difficult-to-treat asthma

Table 1 Program objectives and key messages

\begin{tabular}{ll}
\hline Program objectives & Increase GP knowledge about difficult-to-treat \\
& asthma and its subtypes \\
& Increase the proportion of GPs who can identify \\
& patients with poorly controlled asthma \\
& Increase the proportion of GPs who can identify \\
& severe asthma cases within the broader \\
& difficult-to-treat asthma group \\
& Increase awareness of benefits of referral to \\
& respiratory specialists for patients with severe, \\
& high risk or difficult-to-treat asthma \\
& Identify patients with uncontrolled or \\
& difficult-to-treat asthma \\
& Assess and manage factors contributing to poor \\
Key messages & difficult-to-treat and severe asthma) \\
& Consider referral to a specialist respiratory \\
& physician for people with severe, high-risk or \\
& difficult-to-treat asthma.
\end{tabular}

b) a discussion guide for the educational visitors to help facilitate and guide discussions within the meeting.

Ten experienced educational visitors were trained to deliver the educational program through background reading and a half-day training workshop including role playing and case discussion. Throughout delivery of the educational program, the educational visitors received ongoing clinical support from the program team via an online discussion forum and regular teleconferences.

The educational program was accredited as continuing professional development with the peak Australian general practice colleges.

\section{Evaluation \\ Data collection}

We designed a retrospective pre-test (RPT) with postsurvey to measure changes in GP knowledge, attitudes and practice following the educational program [22-27]. The RPT approach asks GPs to assess what they know or would do from two viewpoints - BEFORE and AFTER participating in the educational program. The questionnaire (Additional file 2) included questions that related to GP understanding of poorly controlled asthma, how GPs approach interactions with patients with poorly controlled asthma, and their knowledge and confidence in managing patients with difficult-to-treat asthma. ${ }^{1}$ The questionnaire was developed with GP and respiratory specialist input.

The questionnaire was initially administered via an online survey three weeks after the educational visit with up to two electronic reminders. After the first $443 \mathrm{GP}$ visits the response rate was $10 \%$, raising concerns about the representativeness of data on changes in GP knowledge, attitudes and practice. For subsequent visits, GPs were provided with a paper copy of the questionnaire at completion of the educational visit, and they received an email reminder one week after the visit with a link to an electronic version of the survey. To maximise the response rate, GPs were provided with the option to return the survey at a time most convenient for them (i.e., directly after the visit, or later by fax, mail or online).

\section{Ethics and consent}

Ethics approval for the questionnaire, and its amendment following the change to data collection, was obtained from the Royal Australian College of General Practitioners National Research and Evaluation Ethics Committee (NREEC 17-018). GPs were provided with

\footnotetext{
${ }^{1}$ The questionnaire also included compulsory questions required for continuing professional development accreditation, however we do not report on these in this paper
} 
an information sheet that explained the study and highlighted that survey completion implied consent. Written consent to participate was therefore not obtained from participating GPs.

\section{Data analysis}

We analysed the survey data using SPSS statistical software (IBM, version 23). Descriptive statistics were calculated for each survey item and McNemar's test was used for paired comparisons [28]. No adjustment was made for multiple comparisons.

We also compared the survey data for the GPs who received the online survey three weeks after the educational visit and those GPs who received the paper survey directly after the educational visit. Most responses were consistent between both groups.

\section{Results}

A total of 1,080 general practice health professionals, including 890 GPs, participated in the educational program, in a total of 185 visits. Overall 226 GPs (25\%) completed the survey, though not all GPs answered every question. Of these, $48 \%(n=108)$ were male and $52 \%(n=115)$ were female. GP survey respondents had practised for an average of 15.7 years, saw an average of 113 patients per week and a median of 10 patients with asthma per week. Overall, most GPs were entirely satisfied with the educational visit $(96 \%, n=214)$.

\section{Understanding of asthma definitions}

GP understanding of the different asthma terms was mixed following the educational visit (Table 2). GPs could select more than one asthma definition per statement though most GPs appropriately identified uncontrolled asthma $(76 \%, n=168)$ and difficult-to-treat asthma $(69 \%, n=154)$. However, $43 \%$ of GPs selected severe asthma for statement 2 which is most appropriately described as difficult-to-treat asthma. Of those selecting difficult-to-treat asthma for this statement, 69\% chose this as their sole option and $17 \%$ additionally selected severe asthma (data not shown), which is not the most correct response. Similarly, for statement 3, which describes a patient with severe asthma, $56 \%$ of GPs $(n=124)$ appropriately identified this, however $45 \%$ also selected difficult-to-treat asthma $(n=100)$. Of those selecting severe asthma, 70\% chose this as their sole option and $10 \%$ also selected difficult-to-treat asthma (data not shown).

\section{Asthma management}

After participating in the educational visit, more GPs identified factors associated with poor asthma control (Table 3). The largest increase was seen in the proportion of GPs who would consider the risk of future adverse outcomes when managing a patient with poorly controlled asthma $(+51 \%)$. This was followed by changes in lifestyle $(+38 \%)$, and self-management strategies $(+35 \%)$. Practice appeared high before the program for some topics where more than $85 \%$ of GP respondents reported already considering trigger factors, medicine adherence and adequate trial of preventer medicines. So minimal change was seen for these factors.

Overall GP knowledge and confidence about managing patients with difficult-to-treat and severe asthma was reported as improving after participating in the educational visit (Table 4). For each survey statement, there was a significant difference $(p \leq 0.001)$ in the proportion of GPs who agreed/strongly agreed with each statement before and after participating in the educational visit.

The greatest knowledge increases related to GP awareness of the biologic therapies that specialists could consider prescribing to their patients with severe asthma (+75\%), of PBS requirements for a patient to be prescribed a biologic therapy $(+73 \%)$, and knowing that patients with different phenotypic characteristics can respond differently to standard therapy $(+67 \%)$.

The proportion of GPs who stated they would be confident in managing a patient they identified as having difficult-to-treat asthma also increased $(+39 \%)$, as did the proportion of GPs who felt they had a good

Table 2 GP selection of asthma definitions for each survey statement after the educational visit $(N=222)$

\begin{tabular}{llll}
\hline Statement ${ }^{\mathrm{a}}$ (Desired response) & $\begin{array}{l}\text { Uncontrolled asthma, } \\
\mathrm{n}(\%)\end{array}$ & $\begin{array}{l}\text { Difficult-to-treat asthma, } \\
\mathrm{n}(\%)\end{array}$ & $\begin{array}{l}\text { Severe asthma, } \\
\mathrm{n}(\%)\end{array}$ \\
\hline $\begin{array}{l}\text { 1. Asthma that includes at least one of the following: poor } \\
\text { symptom control, frequent severe exacerbations, serious } \\
\text { exacerbations and/or airflow limitation (Uncontrolled asthma) }\end{array}$ & $168(76 \%)$ & \\
$\begin{array}{l}\text { 2. Asthma that is uncontrolled despite high-dose ICS/LABA and/or } \\
\text { oral corticosteroids, or that requires such treatment to remain }\end{array}$ & $41(19 \%)$ \\
well controlled (Difficult-to-treat asthma) & $154(69 \%)$ \\
$\begin{array}{l}\text { 3. Asthma that is uncontrolled despite high-dose ICS/LABA and/or } \\
\text { oral corticosteroids and does not improve following appropriate } \\
\text { diagnosis, optimisation of inhaled treatment and/or treatment of } \\
\text { confounders (Severe asthma) }\end{array}$ & $61(28 \%)$ & $100(45 \%)$ \\
\hline
\end{tabular}

Abbreviations: ICS Inhaled corticosteroid, LABA Long-acting beta agonist $_{2}$

${ }^{\mathrm{a}} \mathrm{GPs}$ could select more than one asthma definition per statement 
Table 3 Factors considered by GPs when managing patients with poorly controlled asthma $(N=181)$

\begin{tabular}{llll}
\hline Factors & BEFORE, $\mathrm{n}(\%)$ & NOW, $\mathrm{n}(\%)$ & Difference, $p$ value \\
\hline Risk of future adverse outcomes & $65(36 \%)$ & $158(87 \%)$ & $+51 \% ; p \leq 0.001$ \\
Changes in lifestyle (exercise, weight, etc) & $99(55 \%)$ & $168(93 \%)$ & $+38 \% ; p \leq 0.001$ \\
Self-management strategies & $100(55 \%)$ & $163(90 \%)$ & $+35 \% ; p \leq 0.001$ \\
Confirmation of diagnosis with spirometry & $120(66 \%)$ & $162(90 \%)$ & $+24 \% ; p \leq 0.001$ \\
Use of a written action plan & $122(67 \%)$ & $160(88 \%)$ & $+21 \% ; p \leq 0.001$ \\
Comorbidities & $133(74 \%)$ & $167(92 \%)$ & $+18 \% ; p \leq 0.001$ \\
Inhaler technique & $150(83 \%)$ & $167(92 \%)$ & $+9 \% ; p \leq 0.01$ \\
Adequate trial of preventer medicines & $153(85 \%)$ & $161(89 \%)$ & No difference \\
Medicine adherence & $162(90 \%)$ & $165(93 \%)$ & No difference \\
Trigger factors & $162(90 \%)$ & No difference &
\end{tabular}

understanding of which patients would benefit from referral to a respiratory specialist $(+31 \%)$.

\section{Specialist referral for asthma}

Following participation in the educational program, the proportion of GPs who would refer appropriate patients to a specialist significantly increased (Table 5). The greatest increase was observed in the proportion of GPs who would refer their patient to a specialist when they thought their patient might have severe asthma and could be a candidate for treatment with a biologic therapy. Before the visit, $24 \%$ of GPs considered referral in this case, and afterwards $98 \%$ would, representing an increase of $75 \%$ $(p \leq 0.001)$. In many situations, a large proportion of GPs already appeared to appropriately refer their patients to specialists prior to the education program. However, significantly greater proportions of GPs would consider appropriate referrals after the program, with increases of between 11 and $29 \%$ seen $(p \leq 0.05)$.

\section{Discussion}

This educational program sought to improve the assessment and management of patients with difficult-to-treat and severe asthma in Australian primary care. The educational program focused on a systematic approach to difficult-to-treat asthma, including identification, management and referral to specialist care if appropriate. GP knowledge of and confidence in managing patients with difficult-to-treat and severe asthma improved after participating in the educational program. Our evaluation results suggest that, following participation in the program, a greater proportion of GPs felt they better understood the concept of asthma severity and its therapeutic implications, including identification of patients who could benefit from timely referral to a respiratory specialist, and the role of biologic therapy for patients with severe asthma.

The concept of asthma severity is commonly misunderstood in primary care, not surprisingly since this concept has changed substantially over time [9]. While

Table 4 Proportion of GPs agreeing with statements about management of patients with difficult-to-treat and severe asthma

\begin{tabular}{|c|c|c|c|}
\hline Statement & BEFORE, n (\%) & NOW, n (\%) & Difference, $p$ value \\
\hline $\begin{array}{l}\text { I have a good understanding of which patients would benefit } \\
\text { from timely referral to a respiratory specialist }\end{array}$ & $125(66 \%)$ & $214(97 \%)$ & $+31 \% ; p \leq 0.001$ \\
\hline $\begin{array}{l}\text { I understand that different patients with asthma may have } \\
\text { different phenotypic characteristics that can respond differently to } \\
\text { standard therapy }\end{array}$ & $57(30 \%)$ & $212(97 \%)$ & $+67 \% ; p \leq 0.001$ \\
\hline $\begin{array}{l}\text { I am aware of available biologic therapies that respiratory } \\
\text { specialists can consider prescribing to my patients with severe } \\
\text { asthma }\end{array}$ & 39 (21\%) & $210(96 \%)$ & $+75 \% ; p \leq 0.001$ \\
\hline $\begin{array}{l}\text { I have a good understanding of the role of GPs and specialists in } \\
\text { collaboratively managing a patient with severe asthma who } \\
\text { requires biologic therapy }\end{array}$ & $84(44 \%)$ & 202 (91\%) & $+47 \% ; p \leq 0.001$ \\
\hline $\begin{array}{l}\text { I would feel confident managing a patient I have identified as } \\
\text { having difficult-to-treat asthma }\end{array}$ & $90(49 \%)$ & $195(88 \%)$ & $+39 \% ; p \leq 0.001$ \\
\hline $\begin{array}{l}\text { I understand the PBS requirements for a patient to be prescribed a } \\
\text { biologic therapy for severe asthma }\end{array}$ & $24(13 \%)$ & $191(86 \%)$ & $+73 \% ; p \leq 0.001$ \\
\hline
\end{tabular}


Table 5 Proportion of GPs who consider referring a patient to a respiratory specialist in specific situations $(N=179)$

\begin{tabular}{|c|c|c|c|}
\hline Situation & BEFORE, n (\%) & NOW, n (\%) & Difference, $p$ value \\
\hline $\begin{array}{l}\text { I believe the patient may have severe asthma and may be a } \\
\text { candidate for treatment with a biologic therapy }\end{array}$ & $42(24 \%)$ & $176(98 \%)$ & $+75 \%, p \leq 0.001$ \\
\hline I suspect the patient has occupational asthma & $101(56 \%)$ & $152(85 \%)$ & $+29 \%, p \leq 0.001$ \\
\hline $\begin{array}{l}\text { The patient is at high risk of future adverse asthma-related } \\
\text { outcomes }\end{array}$ & $109(61 \%)$ & $159(89 \%)$ & $+28 \%, p \leq 0.001$ \\
\hline $\begin{array}{l}\text { I have addressed comorbidities I can treat and have not seen an } \\
\text { improvement in asthma control }\end{array}$ & $116(65 \%)$ & $159(89 \%)$ & $+24 \%, p \leq 0.001$ \\
\hline $\begin{array}{l}\text { The patient requires high-dose inhaled corticosteroids to maintain } \\
\text { asthma control despite correct inhaler technique and good } \\
\text { adherence }\end{array}$ & $117(65 \%)$ & $145(81 \%)$ & $+16 \%, p \leq 0.001$ \\
\hline $\begin{array}{l}\text { I am unsure of the asthma diagnosis (e.g., patients with features of } \\
\text { both asthma and } \operatorname{COPD}^{\mathrm{a}} \text { ) }\end{array}$ & $132(74 \%)$ & $151(84 \%)$ & $+11 \%, p=0.018$ \\
\hline $\begin{array}{l}\text { I have been treating the patient for } 12 \text { months or more with little } \\
\text { to no improvement in symptoms }\end{array}$ & $146(82 \%)$ & $158(88 \%)$ & $+7 \%$, No significant difference \\
\hline
\end{tabular}

${ }^{a}$ Chronic obstructive pulmonary disease

GPs reported that their knowledge of managing patients with difficult-to-treat and severe asthma increased, their understanding of asthma classification was mixed following the educational program, specifically their knowledge of the definitions of asthma severity. This is not surprising given the complexity of assessing asthma severity: defining severity based upon intensity of treatment, and retrospectively applying a severity label after 3-6 months treatment is not a common method for classifying the severity of other diseases. This issue is further confounded by the common use of several severity descriptors for other features such as the intensity and frequency of symptoms, severity of exacerbations (e.g., 'acute severe asthma') and degree of obstruction (e.g., 'severe airflow limitation') [29]. As frequent and severe symptoms may rapidly become well controlled with optimised ICS therapy for many patients, these features at the time of presentation cannot be considered to reflect underlying severe disease. The distinction between difficult-to-treat and severe asthma also has important therapeutic implications: biologic therapies in Australia are reserved only for those with specific phenotypes of severe asthma who are likely to respond. However, many patients presenting with difficult-to-treat asthma are likely to improve with less costly interventions, such as managing comorbidities. Additional education in these areas might be worth considering for future programs.

Consideration of factors contributing to poor asthma control is an important step in the systematic approach to difficult-to-treat asthma. Self-reported measures of GP awareness of these factors improved following the educational program. This has important clinical implications for improving patient outcomes as recent studies have found that one-third of patients with doctordiagnosed asthma had no evidence of asthma after objective assessment [30]; almost half of patients with difficult-to-treat asthma were non-adherent to their asthma preventers [31]; and only $31 \%$ of patients with asthma demonstrated correct inhaler technique [32]. Despite the clinical significance of comorbidities that can mimic asthma or worsen asthma control, they are commonly under-recognised in difficult-to-treat asthma [33]. Detection of these is an essential component of the systematic evaluation of asthma, as management of comorbidities such as gastro-oesophageal reflux disease, rhinitis, chronic rhinosinusitis and obesity can often be initiated in primary care.

Diagnosis and management of patients with difficultto-treat and severe asthma requires coordinated efforts between primary and secondary care [34]. It is important therefore that GPs can identify appropriate patients who may benefit from timely referral to specialist care for review and potential consideration of biologic therapy. Our results highlight a low baseline level of awareness of the role of biologic therapy in severe asthma, which may disadvantage those patients who stand to benefit from timely access to these medicines. With the promise of additional therapies for severe asthma, these findings support further education to improve access.

Although these results demonstrate self-reported understanding and intended behaviour rather than longterm practice and outcomes, they do suggest that when GPs who participated in the program are presented with patients whose asthma is poorly controlled they will now, on their own assessment, be better equipped to manage these patients more appropriately.

The RPT design was chosen as the most appropriate method to evaluate this program as it can overcome important biases such as response shift bias. It is viewed as at least equivalent to, or by some authors, as superior to traditional pre and post survey comparisons and is a pragmatic choice when time and/or resources are 
limited [25, 26, 35]. Potential limitations of the RPT method are the biases that can be introduced into the data, including effort justification, social desirability and recall bias, although the latter is less likely to be an issue in this particular evaluation [36-38]. Additional limitations of the survey relate to data being self-reported, as described above, and the ethics-approved change in the method of data collection, as described in the Methods. This change resulted in an increased survey response rate, with an overall response rate of $25 \%$ when the survey was administered at the end of the visit compared with $10 \%$ for the initial surveys that were administered by email 3 weeks post-visit. In recent years there has been an overall decline in survey response rates among Australian GPs [39], thought to be partly due to increased workloads and an increasing number of requests to complete surveys [40]. Actual changes in GP behaviour could not be measured. Other study designs would be required to detect longer term changes in GP practice or patient outcomes such as quality of life, asthma exacerbations or changes in asthma hospitalisations, to determine if education programs that focus on complex chronic conditions such as asthma can impact patient outcomes.

\section{Conclusions}

This educational program improved GP knowledge, confidence and intended practice in managing patients with difficult-to-treat and severe asthma. As a result of the educational program, GPs indicated an increase in knowledge and confidence to: identify patients with difficult-to-treat asthma and severe asthma; address modifiable factors that may contribute to poor asthma control; and identify and refer patients who may benefit from timely specialist referral. Overall, this study demonstrates the value of an educational program that focuses on the management of complex clinical areas and highlights the value of ongoing education in these areas.

\section{Additional files}

Additional file 1: The GP handout provided to GPS as part of the educational visit. (PDF $869 \mathrm{~kb}$ )

Additional file 2: The RPT questionnaire provided to GPS at the end of the educational visit. (PDF $385 \mathrm{~kb}$ )

\section{Abbreviations}

COPD: Chronic obstructive pulmonary disease; GP: General practitioner; ICS: Inhaled corticosteroid; LABA: Long-acting beta 2 agonist; PBS: Pharmaceutical Benefits Scheme; RPT: Retrospective pre-test

\section{Acknowledgements}

We would like to acknowledge and thank Michelle Koo, Kirsty Lembke, Tara De Konig, Alistair Gunn and other NPS MedicineWise staff for their contributions to the program, NPS MedicineWise educational visitors for delivering the educational program, and the GPs who participated in the program and provided feedback.

\section{Authors' contributions}

$\mathrm{JM}, \mathrm{KS}, J \mathrm{Y}, \mathrm{HR}$ and $\mathrm{CW}$ were involved in the design and planning of the program and the study. $\mathrm{KS}$ and $\mathrm{IH}$ conducted data analysis and interpretation. $\mathrm{IH}$ and $\mathrm{JM}$ drafted the initial manuscript. All other authors reviewed and approved the manuscript prior to submission.

\section{Funding}

Funding for this project was provided by AstraZeneca Pty Ltd. and Novartis Pharmaceuticals Australia Pty Ltd. to VentureWise Pty Ltd. VentureWise commissioned NPS MedicineWise to design, develop and implement this project with complete independence from the funding source. AstraZeneca and Novartis Pharmaceuticals had no involvement in the data analysis and interpretation, educational program or in the drafting of the article.

\section{Availability of data and materials}

The datasets generated and analysed during the current study are not publicly available due to ethical restrictions.

\section{Ethics approval and consent to participate}

Ethics approval for the questionnaire, and its amendment following the change to data collection, was obtained from the Royal Australian College of General Practitioners National Research and Evaluation Ethics Committee (NREEC 17-018). GPs were provided with an information sheet that explained the study and highlighted that survey completion implied consent. Written consent to participate was therefore not obtained from participating GPS.

\section{Consent for publication}

Not applicable.

\section{Competing interests}

Author HR or her institute have received honoraria for providing independent advice on advisory boards, steering committees and data safety monitoring board for AstraZeneca, Boehringer Ingelheim, GlaxoSmithKline, Merck and Novartis; independent consulting for AstraZeneca and GlaxoSmithKline; for providing independent medical education at symposia funded by AstraZeneca, Boehringer Ingelheim, GlaxoSmithKline, Mundipharma, Novartis and Teva. Her institute has received independent research grants from AstraZeneca and GlaxoSmithKline. She has participated in a Novartis-funded severe asthma registry study.

\section{Author details}

${ }^{1}$ NPS MedicineWise, PO Box 1147, Strawberry Hills, NSW 2012, Australia. ${ }^{2}$ Woolcock Institute of Medical Research, The University of Sydney, Sydney, NSW 2006, Australia.

Received: 19 February 2019 Accepted: 8 July 2019

Published online: 13 July 2019

References

1. National Health Survey: First Results, Australia 2017-18. 2018. http://www. abs.gov.au/ausstats/abs@.nsf/mf/4364.0.55.001. Accessed 6 Nov 2018.

2. Reddel HK, Sawyer SM, Everett PW, Flood PV, Peters MJ. Asthma control in Australia: a cross-sectional web-based survey in a nationally representative population. Med J Aust. 2015;202(9):492-7.

3. McDonald VM, Maltby S, Reddel HK, King GG, Wark PA, Smith L, Upham JW James AL, Marks GB, Gibson PG. Severe asthma: current management, targeted therapies and future directions-a roundtable report. Respirology. 2017;22(1):53-60.

4. Australian Asthma Handbook, Version 1.3. http://www.asthmahandbook.org. au/. Accessed 31 Jan 2019.

5. Global Initiative for Asthma. Global Strategy for Asthma Management and Prevention, 2018. https://ginasthma.org/wp-content/uploads/2019/01/2018GINA.pdf. Accessed 22 Oct 2018.

6. Chung KF, Wenzel SE, Brozek JL, Bush A, Castro M, Sterk PJ, Adcock IM, Bateman ED, Bel EH, Bleecker ER, et al. International ERS/ATS guidelines on definition, evaluation and treatment of severe asthma. Eur Respir J. 2014;43(2):343-73

7. Israel E, Reddel HK. Severe and difficult-to-treat asthma in adults. N Engl J Med. 2017;377(10):965-76. 
8. Reddel HK, Taylor DR, Bateman ED, Boulet LP, Boushey HA, Busse WW Casale TB, Chanez P, Enright PL, Gibson PG, et al. An official American Thoracic Society/European Respiratory Society statement: asthma control and exacerbations: standardizing endpoints for clinical asthma trials and clinical practice. Am J Respir Crit Care Med. 2009;180(1):59-99.

9. Taylor DR, Bateman ED, Boulet L-P, Boushey HA, Busse WW, Casale TB, Chanez P, Enright PL, Gibson PG, de Jongste JC, et al. A new perspective on concepts of asthma severity and control. Eur Respir J. 2008;32(3):545-54.

10. Drazen JM, Harrington D. New biologics for asthma. N Engl J Med. 2018:378(26):2533-4.

11. Upham JW, Chung LP. Optimising treatment for severe asthma. Med J Aust. 2018;209(2 suppl):S22-S7.

12. Pharmaceutical Benefits Scheme. Mepolizumab. http://www.pbs.gov.au/ medicine/item/10980X-10996R-11003D-11014Q. Accessed 15 Nov 2018.

13. Pharmaceutical Benefits Scheme. Omalizumab. http://www.pbs.gov.au/ medicine/item/10110D-10118M-10956P-10967F. Accessed 15 Nov 2018.

14. Pharmaceutical Benefits Scheme. Benralizumab. http://www.pbs.gov.au/ medicine/item/11504L-11523L-11529T-11549W. Accessed 4 Dec 2018.

15. Medicinelnsight. www.medicineinsight.org.au. Accessed 11 Oct 2018.

16. Chidwick K, Kiss D, Gray R, Yoo J, Aufgang M, Zekry A. Insights into the management of chronic hepatitis C. Aust J Gen Pract. 2018;47:639-45.

17. González-Chica DA, Vanlint S, Hoon E, Stocks N. Epidemiology of arthritis, chronic back pain, gout, osteoporosis, spondyloarthropathies and rheumatoid arthritis among 1.5 million patients in Australian general practice: NPS MedicineWise Medicinelnsight dataset. BMC Musculoskelet Disord. 2018;19(1):20

18. NPS MedicineWise, General Practice Insights Report July 2016-June 2017: A working paper. https://www.nps.org.au/medicine-insight/usingmedicineinsight-data. Accessed 14 Feb 2019.

19. The Second Australian Atlas of Healthcare Variation 2017. https://www. safetyandquality.gov.au/atlas/atlas-2017/. Accessed 10 Oct 2018.

20. O'Brien MA, Rogers $\mathrm{S}$, Jamtvedt G, Oxman AD, Odgaard-Jensen J, Kristoffersen DT, Forsetlund L, Bainbridge D, Freemantle N, Davis D, et al. Educational outreach visits: effects on professional practice and health care outcomes. Cochrane Database Syst Rev. 2007;4:CD000409.

21. Soumerai SB, Avorn J. Principles of educational outreach ('academic detailing') to improve clinical decision making. JAMA. 1990;263(4):549-56.

22. Bhanji F, Gottesman R, de Grave W, Steinert Y, Winer LR. The retrospective pre-post: a practical method to evaluate learning from an educational program. Acad Emerg Med. 2012;19(2):189-94.

23. Davis GA. Using a retrospective pre-post questionnaire to determine program impact. J Ext. 2003;41(4). https://www.joe.org/joe/2003august/tt4. php. Accessed 11 July 2019.

24. Klatt J, Taylor-Powell E. Synthesis of literature relative to the retrospective pretest design. Toronto: Presentation to the 2005 Joint CES/AEA Conference; 2005

25. Lamb T. The retrospective pretest: an imperfect but useful tool. Eval Exchange. 2005;11(2):18-9.

26. Pratt CC, McGuigan WM, Katzev AR. Measuring program outcomes: using retrospective pretest methodology. Am J Eval. 2000;21(3):341-9.

27. Rockwell SK, Kohn H. Post-then-pre evaluation. J Ext. 1989;27(2):19-21.

28. Adedokun OA, Burgess WD. Analysis of paired dichotomous data: a gentle introduction to the McNemar test in SPSS. J Multidiscip Eval. 2011;8(17):125-31.

29. Taylor DR, Bateman ED, Boulet LP, Boushey HA, Busse WW, Casale TB, Chanez $\mathrm{P}$, Enright $\mathrm{PL}$, Gibson $\mathrm{PG}$, de Jongste $J \mathrm{C}$, et al. A new perspective on concepts of asthma severity and control. Eur Respir J. 2008;32(3):545-54.

30. Aaron SD, Vandemheen KL, FitzGerald JM, Ainslie M, Gupta S, Lemiere C, Field SK, Mclvor RA, Hernandez P, Mayers I, et al. Reevaluation of diagnosis in adults with physician-diagnosed asthma. JAMA. 2017;317(3):269-79.

31. Lee J, Tay TR, Radhakrishna N, Hore-Lacy F, Mackay A, Hoy R, Dabscheck E, O'Hehir R, Hew M. Nonadherence in the era of severe asthma biologics and thermoplasty. Eur Respir J. 2018;51(4):1701836.

32. Sanchis J, Gich I, Pedersen S. Systematic review of errors in inhaler use: has patient technique improved over time? Chest. 2016:150(2):394-406.

33. Radhakrishna N, Tay TR, Hore-Lacy F, Stirling R, Hoy R, Dabscheck E, Hew M. Validated questionnaires heighten detection of difficult asthma comorbidities. J Asthma. 2017;54(3):294-9.

34. Tay TR, Lee JW-Y, Hew M. Diagnosis of severe asthma. Med J Aust. 2018;209(2 Suppl):S3-S10.
35. Allen JM, Nimon K. Retrospective pretest: a practical technique for professional development evaluation. J Ind Teach Educ. 2007:44(3):27-42.

36. Hill LG, Betz DL. Revisiting the retrospective pretest. Am J Eval. 2005;26(4):501-17.

37. Lam TC, Bengo P. A comparison of three retrospective self-reporting methods of measuring change in instructional practice. Am J Eval. 2003;24(1):65-80.

38. Nimon K, Zigarmi D, Allen J. Measures of program effectiveness based on retrospective pretest data: are all created equal? Am J Eval. 2011;32(1):8-28.

39. Parkinson A, Jorm L, Douglas KA, Gee A, Sargent GM, Lujic S, McRae IS. Recruiting general practitioners for surveys: reflections on the difficulties and some lessons learned. Aust J Prim Health. 2015;21(2):254-8.

40. Crouch S, Robinson P, Pitts M. A comparison of general practitioner response rates to electronic and postal surveys in the setting of the nationa STI prevention program. Aust N Z J Public Health. 2011;35(2):187-9.

\section{Publisher's Note}

Springer Nature remains neutral with regard to jurisdictional claims in published maps and institutional affiliations.

Ready to submit your research? Choose BMC and benefit from:

- fast, convenient online submission

- thorough peer review by experienced researchers in your field

- rapid publication on acceptance

- support for research data, including large and complex data types

- gold Open Access which fosters wider collaboration and increased citations

- maximum visibility for your research: over $100 \mathrm{M}$ website views per year

At $\mathrm{BMC}$, research is always in progress.

Learn more biomedcentral.com/submissions 